\title{
Outcomes of transvaginal multifetal pregnancy reduction without injecting potassium chloride
}

\author{
Devika Gunasheela ${ }^{1}$, Sneha Rao ${ }^{1}$, Geethika Jain ${ }^{1}$, Anitha GS ${ }^{2 *}$
}

\begin{abstract}
${ }^{1}$ Department of Obstetrics and Gynecology, Gunasheela Hospital, Bangalore, Karnataka, India
${ }^{2}$ Department of Obstetrics and Gynecology, ESIPGIMS and R, Bangalore, Karnataka, India
\end{abstract}

Received: 24 October 2016

Accepted: 23 November 2016

*Correspondence:

Dr. Anitha GS,

E-mail: aninaik85@gmail.com

Copyright: (c) the author(s), publisher and licensee Medip Academy. This is an open-access article distributed under the terms of the Creative Commons Attribution Non-Commercial License, which permits unrestricted non-commercial use, distribution, and reproduction in any medium, provided the original work is properly cited.

\section{ABSTRACT}

Background: Assisted reproductive technologies and the use of fertility drugs have significantly increased the prevalence of multiple pregnancy in last three decades. Various techniques and routes have been studied so far regarding fetal reduction to achieve healthy viable pregnancy. The current study aims to study different outcomes of multifetal pregnancy reduction without injecting potassium chloride.

Methods: Total 57 patients were studied from October 2011 to November 2012 at our centre. 28 were higher order pregnancies who consented for fetal reduction and 29 were nonreduced twins as control group. It was a prospective comparative study. Fetal reduction was done transvaginally between 8-12 weeks by intracardiac puncture followed by manual aspiration of embryonic parts till asystole. Use of $\mathrm{KCl}$ was avoided. The most easily accessible sac was chosen for reduction. All were reduced to twins. Reduction to singleton and selective reduction of anomalous fetus were removed from the study as it could have created a bias in the comparison. The primary outcomes like miscarriage, post procedure complications, mean gestational age at delivery, preterm delivery, mean birth weight were studied. The outcomes of reduced twins were compared with that of nonreduced twins. The various secondary outcomes like IUGR, take home baby rate, neonatal morbidity, mortality, maternal morbidity and mortality, associated obstetric complications were studied.

Results: Both groups were comparable with respect to age and parity. The average gestation of fetal reduction was 9.46 weeks. Abortion rate was $17.9 \%(n=5)$ in reduced group which was statistically significant. 4 patients were lost to follow up. There were no statistically significant differences with regard to cesarean section rate, preterm delivery, mean birth weight, mean gestational delivery between two groups. No incidence of IUGR in the series. One baby died in the control group, none in reduced group. Take home baby rate $79.1 \%$. Overall the antenatal and post-operative complications were higher in control group than in reduced but it was not statistically significant.

Conclusions: Fetal reduction is a feasible option for triplets and higher orders multiple pregnancies. Use of $\mathrm{KCl}$ is not mandatory for multifetal pregnancy reduction. It is best avoided as there are increased rates of preterm labour and PPROM. There is increase in abortion rate after multifetal pregnancy reduction in comparison to nonreduced twins. So couple should be counseled about the probability of losing the entire pregnancy. The obstetric and neonatal outcomes of reduced and nonreduced twins are comparable, thus fetal reduction as a procedure is not adding any extra risk on pregnancy outcome.

Keywords: Potassium chloride, Transvaginal multifetal pregnancy

\section{INTRODUCTION}

Multifetal pregnancy reduction is a procedure designed to decrease the number of live fetuses in higher order multiples to improve the outcomes of pregnancies. The procedure has proved to be both safe and effective. But the long term outcomes of surviving fetuses are still not known. ${ }^{1,2}$ 
The term "multifetal pregnancy reduction" has become widely accepted and has been adopted in the most recent Committee opinion of the American College of Obstetricians and Gynecologists on the subject ${ }^{3}$, and it is believed that it should be used whenever the reduction of an apparently normal fetus is performed in an attempt to reduce the risk of premature delivery of other fetuses in the same uterus.

Fetal reduction can be done in the first trimester or second trimester. First trimester reduction can be early between 8-10 weeks or late between 10- 12 weeks.

Early reductions are technically easy, can be done transvaginally Less than 8 weeks, there are chances of spontaneous reduction of fetuses and missed abortion. Hence fetal reduction should be best done after 8 weeks. Most of the morphologic abnormalities cannot be detected at this stage.

Another option is late first trimester reduction which could be done around 11-12 weeks after NT/NTD scan which provides additional information about abnormal fetus. However, late reductions are difficult and time consuming.

Majority of second trimester reductions are done by transabdominal route either mechanically or with $\mathrm{KCl}$ or $\mathrm{NaCl}$. Multifetal pregnancy reduction can be performed transcervically, transvaginally or transabdominally. Transcervical method involves mechanical dilatation of cervix, followed by embryonic aspiration with karmans cannula or metal cannula. This method is no longer used because of the increased risk of chorioamnionitis, miscarriage, spotting. ${ }^{4}$

Transabdominal multifetal pregnancy reduction procedures are generally carried out between 10 and 13 weeks. It is technically more difficult to perform transabdominal procedures before 10 weeks because the uterus is confined to the pelvis and greater distance involved in reaching the fetuses from maternal abdominal wall. Transabdominal route requires more skill compared to transvaginal route especially in the earlier part of the learning period ${ }^{4}$

The transvaginal technique is performed between $7^{\text {th }}$ and $11^{\text {th }}$ weeks, by injecting $\mathrm{NaCl}$ or $\mathrm{KCl}$ solution into the fetal thorax ${ }^{4}$.2-3 cc of hypertonic KCL is injected till asystole is observed over 3-5 mins. The injection of such substances into the embryo or fetal thorax is not a risk free procedure as cases of anencephaly, ${ }^{5}$, limb amputation $^{6}$ and total pregnancy loss ${ }^{7}$ have been described. Moreover $\mathrm{KCl}$ is not strictly limited to fetal heart; it can diffuse into the amniotic sac and adjacent gestational sacs. $\mathrm{KCl}$ can induce release of tissue plasminogen activator in the hypothalamo neurohypophyseal system and up regulation in MMP-9 activity in the retina, which promotes retinal damage. By inducing matrix degrading enzymes in the uterus and inducing cytokines, KCL can cause pregnancy loss, preterm delivery and PPROM. ${ }^{8}$

Alternatively transvaginal intracardiac puncture till asystole without aspiration of embryonic parts or amniotic fluid done between 7 to 9 weeks by Iberico et al 2000 showed mean gestational age at delivery of 35 weeks, take home baby rate of $89 \%$, less inflammation due to less trophoblastic detachment, less post-operative infection and spotting. The method was less time consuming. Similar findings noted by various other studies. Fetal reduction is less studied in Indian context. Hence this current study was undertaken to study the various outcomes of fetal reduction by intracardiac puncture in Indian scenario.

\section{METHODS}

Between October 2011 and Dec 2012; the outcomes of multifetal pregnancy reduction was studied in Gunasheela maternity and surgical hospital, Bangalore. Patients with non-reduced twins were recruited as control group. This study was a prospective comparative study.

All the patients with triplets and higher order multiples were counselled in detail about the procedure, type and duration of anesthesia, possible complications, chance of success and possible need for follow up therapy, psychological and economic aspects.

A detailed written and verbal consent was obtained from all participating couples. Detailed history, general examination, obstetric examination and bimanual examination, ultrasound to confirm number of fetuses, period of gestation, chorionicity, fetal heart beat, any anomalies, and routine blood investigations was done for all patients.

A routine transvaginal ultrasound confirming the number of fetuses and cardiac activity was performed before the procedure. All procedures were done between 8- 11 weeks with ALOKA 500 (Figure 1) ultrasound machine equipped with a $7.5 \mathrm{MHz}$ transvaginal transducer (Figure 2 ) and puncture guide. Under spinal anesthesia patients were placed in lithotomy position. Surgical field was cleaned with $10 \%$ povidone iodine followed by normal saline and draped. The fetuses were visualized to know the number of fetuses, position of the sacs, size and cardiac activity (Figure 3). 16 gauze 12 inch long oocyte pick up needle (Figure 4) was introduced through a guide attached to the ultrasound. The most easily accessible fetus was selected and intra cardiac puncture was done with OPU needle. Manual aspiration with 20cc syringe was done till asystole was confirmed. Use of potassium chloride or sodium chloride solution into the sac was avoided. Those in whom $\mathrm{NaCl}$ or $\mathrm{KCl}$ was used were excluded from the study. Time factor didn't matter in our study. All the procedures were over between 20-30 minutes. Once the asystole was confirmed and the viability of remaining fetuses was checked, the OPU 
needle was withdrawn. All women were given IV prophylactic antibiotics before the procedure and post procedure with oral antibiotics for 6 days. All women were given 2 doses of inj terbutaline $0.25 \mathrm{mg}$ s.c BD after the procedure followed by tablet ritodrine or terbutaline BD for next 7 day. Women were discharged from the hospital on the next day after the check scan for number of viable fetuses and retroplacental bleeding. If any retroplacental bleeding was noticed, the patients were treated with haemostatics and discharged once bleeding reduced. Follow up scan was done after a week. The patients were asked to review if any leak or watery discharge, bleeding per vaginum, fever, lower abdomen pain, foul smelling discharge, uterine tenderness. The obstetric complications and medical illness were noted, and treated accordingly.

The obstetric complications and medical illness were noted, and treated accordingly in their follow up visits throughout antenatal period. The mode of delivery, indications, and fetal birth were compared with the nonreduced group. The observations of our study were compared with similar study.

\section{Inclusion criteria}

All patients with higher order multiple gestations (3 or more fetuses) as study group.

All nonreduced twin gestations as control group

Intracardiac puncture followed by manual aspiration of embryonic parts as the method

\section{Exclusion criteria}

Using $\mathrm{KCl}$ or $\mathrm{NaCl}$.

Fetal reduction of twins to singleton pregnancies

\section{Statistical methods}

Descriptive and inferential statistical analysis has been carried out in the present study. Results on continuous measurements are presented on Mean \pm SD (Min-Max) and results on categorical measurements are presented in Number (\%). Significance is assessed at $5 \%$ level of significance

\section{Statistical software}

The Statistical software namely SAS 9.2, SPSS 15.0, Stata 10.1, MedCalc 9.0.1 ,Systat 12.0 and $\mathrm{R}$ environment ver.2.11.1 were used for the analysis of the data and Microsoft word and Excel have been used to generate graphs, tables etc ${ }^{9,10}$

\section{RESULTS}

Total 57 patients were recruited for the study. 28 were higher order pregnancies in the test group who underwent reduction and 29 were non reduced twins as control group. However, one patient with monochorionic diamniotic pregnancy underwent reduction of triplets to single, so she was excluded from the study as it could have created a bias in the comparison .It is a prospective comparative study.

Table 1: Age distribution of patients.

\begin{tabular}{|llll|}
\hline $\begin{array}{l}\text { Age in } \\
\text { years }\end{array}$ & Group FR & $\begin{array}{l}\text { Group no } \\
\text { FR }\end{array}$ & Total \\
\hline $21-25$ & $3(10.7 \%)$ & $6(20.7 \%)$ & $9(15.8 \%)$ \\
\hline $26-30$ & $17(60.7 \%)$ & $14(48.3 \%)$ & $31(54.4 \%)$ \\
\hline $31-35$ & $6(21.4 \%)$ & $8(27.6 \%)$ & $14(24.6 \%)$ \\
\hline $36-40$ & $2(7.1 \%)$ & $0(0 \%)$ & $2(3.5 \%)$ \\
\hline$>40$ & $0(0 \%)$ & $1(3.4 \%)$ & $1(1.8 \%)$ \\
\hline Total & $28(100 \%)$ & $29(100 \%)$ & $57(100 \%)$ \\
\hline $\begin{array}{l}\text { Mean } \pm \\
\text { SD }\end{array}$ & $29.57 \pm 3.69$ & $28.83 \pm 4.31$ & $29.21 \pm 3.97$ \\
\hline
\end{tabular}

Samples are age matched with $\mathrm{p}=0.488$.

Majority of the patients were between 26-30 years in both groups, followed by 31-35 years. Only 1 patient was $>40$ years. Both groups are comparable. Mean age is $29.5+/-$ 3.69 years in reduced Vs $28.83+/-3.97$ years. In the fetal reduction group, $67.9 \%$ were primigravida $(n=19)$, $32.1 \%(\mathrm{n}=9)$ were multigravida. In the control group, $69 \% \quad(n=20)$ were primigravida, 31\% $(n=9)$ were multigravida.

Table 2: Comparison of parity in two groups of patients.

\begin{tabular}{|llll|}
\hline Parity & Group FR & $\begin{array}{l}\text { Group no } \\
\text { FR }\end{array}$ & Total \\
\hline Primi & $19(67.9 \%)$ & $20(69 \%)$ & $39(68.4 \%)$ \\
\hline Multi & $9(32.1 \%)$ & $9(31 \%)$ & $18(31.6 \%)$ \\
\hline Total & $28(100 \%)$ & $29(100 \%)$ & $58(101.8 \%)$ \\
\hline
\end{tabular}

Parity distribution is statistically similar in two groups with $\mathrm{p}=0.928$.

In the fetal reduction group, $67.9 \%$ were primigravida $(n=19), 32.1 \% \quad(n=9)$ were multigravida. In the control group, $69 \%(n=20)$ were primigravida, $31 \%(n=9)$ were multigravida.

In the fetal reduction group, $42.9 \%(n=12)$ were ICSI pregnancies, $25 \%$ (n-7) were IUI, followed by $10.7 \%$ $(n=3)$ OI+SI. Increased number of multiple pregnancy due to IUI in my study.

In the control group, $48.3 \%(\mathrm{n}=14)$ were ICSI, $13.8 \%$ $(n=4)$ IVM, $10.3 \%$ each of AID and spontaneous conceptions (Table 3 ). 
In the reduction group, majority were triplets, $(n=26), 1$ was quadruplet, 1 was quintuplet. 1 patient with twin pregnancy carrying an anomalous fetus was selectively reduced and another patient of twins reduced to single at request. Hence both were excluded from the study.

In quadruplet pregnancy in bicornuate uterus, 2 sacs in left horn were selectively reduced as left horn was small compared to right horn and was not suitable for pregnancy on previous interval hysteroscopy (Table 4).

Another patient with quintuplets, 3 easily accessible embryos was reduced. In our study maximum 3 embryos have been reduced at a time. No one required repeat reduction.

All patients were reduced to twins, whereas one patient who had monochorionic, diamniotic pregnancy with 2 embryos in one amniotic sac was reduced to singleton. She was excluded from the study

Table 3: Comparison of type of conception in two groups.

\begin{tabular}{|lcc|c|}
\hline Conception & $\begin{array}{c}\text { Group FR } \\
(\mathbf{n = 2 8})\end{array}$ & $\begin{array}{c}\text { Group no } \\
\text { FR } \\
(\mathrm{n}=29)\end{array}$ & $\begin{array}{c}\text { Total } \\
(\mathbf{n}=58)\end{array}$ \\
\hline SPONT & $0(0 \%)$ & $3(10.3 \%)$ & $3(5.3 \%)$ \\
\hline OI+SI & $3(10.7 \%)$ & $1(3.4 \%)$ & $4(7 \%)$ \\
\hline IUI & $7(25 \%)$ & $2(6.9 \%)$ & $9(15.8 \%)$ \\
\hline AID & $1(3.6 \%)$ & $3(10.3 \%)$ & $4(7 \%)$ \\
\hline IVF/ICSI & $12(42.9 \%)$ & $14(48.3 \%)$ & $26(45.6 \%)$ \\
\hline ICSI-DO & $2(7.1 \%)$ & $0(0 \%)$ & $2(3.5 \%)$ \\
\hline IVM & $1(3.6 \%)$ & $4(13.8 \%)$ & $5(8.8 \%)$ \\
\hline FET & $2(7.1 \%)$ & $1(3.4 \%)$ & $3(5.3 \%)$ \\
\hline DET & $0(0 \%)$ & $1(3.4 \%)$ & $1(1.8 \%)$ \\
\hline
\end{tabular}

Table 4: Comparison of starting number of fetuses in two groups.

\begin{tabular}{|llll|}
\hline Starting no & $\begin{array}{l}\text { Group FR } \\
(\mathbf{n}=28)\end{array}$ & $\begin{array}{l}\text { Group no FR } \\
(\mathbf{n}=29)\end{array}$ & $\begin{array}{l}\text { Total } \\
(\mathbf{n}=57)\end{array}$ \\
\hline Quintuplet & 1 & 0 & 1 \\
\hline Quadruplet & 1 & 0 & 1 \\
\hline Triplet & 26 & 0 & 26 \\
\hline Twins & 0 & 29 & 29 \\
\hline
\end{tabular}

Table 5: Distribution of gestation of patients studied in FR group.

\begin{tabular}{|lll|}
\hline Gestation & Number of patients & $\%$ \\
\hline$<8$ weeks & 1 & 3.6 \\
\hline $8-9$ weeks & 4 & 14.3 \\
\hline $9-10$ weeks & 13 & 46.4 \\
\hline $10-12$ weeks & 10 & 35.7 \\
\hline Total & 28 & 100.0 \\
\hline
\end{tabular}

Mean \pm SD: $9.46 \pm 0.81$
Majority of the procedures were done between 9-10 weeks $(n=13)$, followed by $10-12$ weeks $(n=12)$, one patient at $7+6$ weeks. Average gestational age of fetal reduction was $9.4+$ /- 0.81 weeks

All patients in the control group were dichorionic, diamniotic pregnancies.

5 patients aborted in the reduced group, none in control group.Among fetal reduction, 3 patients aborted within a week of fetal reduction. All of them had spotting. 1 patient aborted at 17 weeks, a week after cervical encirclage. One missed abortion at 12 weeks.

Table 6: Distribution of post procedure complications of patients studied in FR group.

\begin{tabular}{|lll|l|}
\hline Complications & $\begin{array}{l}\text { Group } \\
(\mathbf{n}=28)\end{array}$ & $\begin{array}{l}\text { Group no } \\
\text { FR(n=29) }\end{array}$ & $\begin{array}{l}\text { Total } \\
(\mathbf{n}=57)\end{array}$ \\
\hline Abortion & $5(17.9 \%)$ & $0(0 \%)$ & $5(8.8 \%)$ \\
\hline Spotting/bleeding & $3(10.7 \%)$ & $0(0 \%)$ & $3(5.3 \%)$ \\
\hline $\begin{array}{l}\text { Subchorionic } \\
\text { bleeding }\end{array}$ & $3(10.7 \%)$ & $0(0 \%)$ & $3(5.3 \%)$ \\
\hline Fever & $1(3.6 \%)$ & $0(0 \%)$ & $1(1.8 \%)$ \\
\hline
\end{tabular}

$P$ value: 0.023 which is statistically significant.

Table 7: Comparison of delivery in two groups of patients.

\begin{tabular}{|c|c|c|c|c|}
\hline Delivery & $\begin{array}{l}\text { Group } \\
\text { FR } \\
(n=28)\end{array}$ & $\begin{array}{l}\text { Group } \\
\text { no FR } \\
(n=29)\end{array}$ & $\begin{array}{l}\text { Total } \\
(n=57)\end{array}$ & $\begin{array}{l}\mathbf{P} \\
\text { value }\end{array}$ \\
\hline Elective LSCS & $\begin{array}{l}13 \\
(46.4 \%)\end{array}$ & $\begin{array}{l}17 \\
(58.6 \%)\end{array}$ & $\begin{array}{l}30 \\
(52.6 \%)\end{array}$ & 0.599 \\
\hline $\begin{array}{l}\text { Emergency } \\
\text { LSCS }\end{array}$ & $\begin{array}{l}4 \\
(14.3 \%)\end{array}$ & $\begin{array}{l}11 \\
(37.9 \%)\end{array}$ & $\begin{array}{l}15 \\
(26.3 \%)\end{array}$ & $0.060+$ \\
\hline FTND+RMLE & $\begin{array}{l}1 \\
(3.6 \%)\end{array}$ & $\begin{array}{l}1 \\
(3.4 \%)\end{array}$ & $\begin{array}{l}2 \\
(3.5 \%)\end{array}$ & 1.000 \\
\hline $\begin{array}{l}\text { Outlet forceps } \\
+ \text { RMLE }\end{array}$ & $\begin{array}{l}1 \\
(3.6 \%)\end{array}$ & $0(0 \%)$ & $\begin{array}{l}1 \\
(1.8 \%)\end{array}$ & 1.000 \\
\hline $\begin{array}{l}\text { Missed } \\
\text { abortion }\end{array}$ & $\begin{array}{l}1 \\
(3.6 \%)\end{array}$ & $0(0 \%)$ & $\begin{array}{l}1 \\
(1.8 \%)\end{array}$ & 1.000 \\
\hline $\begin{array}{l}\text { Spontaneous } \\
\text { abortion }\end{array}$ & $\begin{array}{l}4 \\
(14.3 \%)\end{array}$ & $0(0 \%)$ & $\begin{array}{l}4 \\
(7 \%)\end{array}$ & 0.111 \\
\hline $\begin{array}{l}\text { Lost to follow } \\
\text { up }\end{array}$ & $\begin{array}{l}4 \\
(14.3 \%)\end{array}$ & $0(0 \%)$ & $\begin{array}{l}4 \\
(7 \%)\end{array}$ & 0.111 \\
\hline
\end{tabular}

In control group, the rate of emergency LSCS increased (37.9 \% vs $14.3 \%$ ) so also elective LSCS (58.6\% vs $46.4 \%)$. It was not statistically significant. Both groups had comparable normal delivery rate. One Outlet forceps delivery in reduced, none in control group.

The preterm delivery between 32-36 weeks was lower than control group. (32.1\% VS 55.2\%). 
3 patients delivered between $28-32$ weeks $(10.7 \%)$ in reduced compared to 2 patients $(6.9 \%)$ in control group. This value was not statistically significant. Mean gestational age at delivery 35.5 weeks in reduced Vs 35.3 weeks. The obstetric and medical complications in control group were more compared to reduced group.

15 babies' required NICU admission, out of which 5 babies required oxygen, 10 babies required ventilator support. The values in both groups are not statistically significant. One baby in control group died on post natal day 7 because of severe prematurity Totally 15 babies required NICU admission, out of which 5 babies required oxygen after delivery ( 2 in reduced Vs 3 in control).

10 babies required ventilator support (4 in reduced Vs 6 in control), 1 baby in control group died on post natal day 7 because of severe prematurity. The mother had chorioamnionitis and underwent emergency LSCS at $27+3$ weeks in view of advanced preterm labour. None of the babies required phototherapy for neonatal jaundice. No neonatal mortality in reduced group.

The mean birth weight in reduced group is $2.2 \mathrm{~kg}$; in control group $2.17 \mathrm{~kg}$ which is comparable overall perinatal and neonatal outcomes are comparable in both the groups.

Take home baby rate in reduced group is $79.1 \%, 98.2 \%$ in control group.

Table 8: Comparison of period of gestation at delivery in two groups of patients.

\begin{tabular}{|lcccc|}
\hline $\begin{array}{l}\text { Period of } \\
\text { gestation }\end{array}$ & $\begin{array}{c}\text { Group } \\
(\mathbf{n}=28)\end{array}$ & $\begin{array}{c}\text { Group no } \\
\text { FR } \\
(\mathbf{n}=29)\end{array}$ & $\begin{array}{c}\text { Total } \\
(\mathbf{n}=57)\end{array}$ & $\begin{array}{c}\text { P } \\
\text { value }\end{array}$ \\
\hline $\begin{array}{l}24-28 \\
\text { weeks }\end{array}$ & $1(3.6 \%)$ & $1(3.4 \%)$ & $2(3.5 \%)$ & 1.000 \\
\hline $\begin{array}{l}28-32 \\
\text { weeks }\end{array}$ & $3(10.7 \%)$ & $2(6.9 \%)$ & $5(8.8 \%)$ & 0.670 \\
\hline $\begin{array}{l}32-36 \\
\text { weeks }\end{array}$ & $9(32.1 \%)$ & $16(55.2 \%)$ & $25(43.9 \%)$ & 0.110 \\
\hline $\begin{array}{l}37-40 \\
\text { weeks }\end{array}$ & $7(25 \%)$ & $10(34.5 \%)$ & $17(29.8 \%)$ & 0.766 \\
\hline $\begin{array}{l}\text { Lost to } \\
\text { follow up }\end{array}$ & $4(14.3 \%)$ & $0(0 \%)$ & $4(7.1 \%)$ & 0.111 \\
\hline
\end{tabular}

\section{DISCUSSION}

The unparelled increase in multifetal pregnancy is the result of ovulation induction drugs and assisted reproductive technologies in the treatment of infertility. It is well accepted that multifetal pregnancies are best avoided by the use of strict criteria for ovulation induction and embryo transfer in invitro fertilization. However, when such pregnancies occur despite adequate precautions, multifetal pregnancy reduction may improve the outcome of these pregnancies.
Embryo reduction is proved to be beneficial for quadruplets and higher order gestations, however there was controversy regarding reduction of triplets to twins. A recent meta-analysis concluded that fetal reduction in triplets is an effective option compared to expectant management. ${ }^{11}$

Mansour et al. conducted a prospective controlled study, included 75 patients with higher order pregnancies from assisted reproduction technique. Controls were 40 nonreduced twin pregnancies and 22 higher order multiple gestations without reductions. First 30 cases were done using potassium chloride and last 45 cases were done by modified method, by aspirating either partially or completely the embryonic parts and avoiding aspirating amniotic fluid. Using the modified technique, the miscarriage rate was lower. The miscarriage rate, fetal wastage rate, mean gestational age and mean birth weight were similar in reduced and non-reduced twins. Overall the outcomes were better in reduced than in non-reduced triplets and quadruplets. ${ }^{12}$

The lower rate of miscarriage in modified method was attributed to the aspiration of embryonic parts at an earlier stage thereby reducing the release of cytokines and prostaglandins, hence reducing the inflammation evoked by left out necrotic tissue on remaining gestational sacs. Moreover $\mathrm{KCl}$ is not strictly limited to fetal heart; it can diffuse into the amniotic sac, and adjacent gestational sacs. $\mathrm{KCl}$ can also induce inflammation

Lee et al, compared the outcomes of various methods of fetal reduction with potassium chloride and without injecting potassium chloride (intracardiac puncture and aspiration of embryonic parts and amniotic fluid) and between early and late fetal reductions. It was a retrospective comparative study. 101 were triplets $(68.2 \%), 33$ were quadruplets $(22.3 \%), 11$ were quintuplets or higher order pregnancies $(7.5 \%)$, and 3 were twins $(2 \%)$. All fetal reductions were performed between 6-16 weeks of gestation.

Mean gestational ages at delivery and birth weights were not different between potassium chloride and nonpotassium chloride groups and between early (less than 8 weeks) and late groups. Non-potassium chloride groups showed a significantly higher take home baby rate (86.1\% Vs 69.7\%, $\mathrm{p}=0.045)$. Immediate loss and pregnancy loss rates were lower in non-potassium chloride groups, but the differences were not statistically significant (5.6\% Vs $10.5 \%$ and $12.5 \%$ Vs $23.7 \%$ ). Early groups showed a lower pregnancy loss rate and a higher take home baby rate, but the differences were not statistically significant. Extreme prematurity rates and PPROM were significantly higher in potassium chloride groups. Early non-potassium chloride group showed a significantly lower immediate loss rate, pregnancy loss rate and PPROM rate and higher take home baby rate. ${ }^{13}$ This study concluded early non $\mathrm{KCl}$ is the best method. 
Table 9: Comparison of results between various KCL studies.

\begin{tabular}{|lllllll|}
\hline Source & Cases & $<24$ weeks & $24-28$ weeks & $28-32$ wks & $32-36 w k s$ & 37 weeks \\
\hline Berkowitz & 200 & $9.5 \%$ & 3 & 6 & 36 & 55 \\
\hline Timor tritsch $^{38}$ & 112 & 12.6 & 7 & 8 & 23 & 62 \\
\hline Lipitz $^{39}$ & 140 & 8.7 & 9.7 & 9.7 & 16.1 & 74 \\
\hline Brambati & 100 & 7 & 3.2 & 10.7 & 29 & 57 \\
\hline Evan S & 1189 & 11.7 & 4.5 & 9 & 32.6 & 42.1 \\
\hline
\end{tabular}

Table 10: Comparison of results of various non KCL studies.

\begin{tabular}{|llllll|}
\hline Mean GA of FR & Lee et al & Mansour & Ibericco & Youseff ${ }^{21}$ & Gunasheela \\
\hline Mean age & 7.8 weeks & 7.2 weeks & 7.8 weeks & $7-11$ weeks & 9.6 weeks \\
\hline Pregnancy loss & 35.4 years & 32.6 years & 33 years & 32.4 years & 29.5 years \\
\hline PPROM & $12.5 \%$ & $8.8 \%$ & $7.4 \%$ & $6.6 \%$ & $17.9 \%$ \\
\hline Birth weight & $10 \%$ & & & & $11.8 \%$ \\
\hline Mean gestation & $2314 \mathrm{~g}$ & $2450 \mathrm{~g}$ & $2304 \mathrm{~g}$ & $2308 \mathrm{~g}$ & $2200 \mathrm{~g}$ \\
\hline Preterm delivery & $36 \mathrm{weeks}$ & $36.9 \mathrm{wks}$ & $35.1 \mathrm{wks}$ & 35.3 weeks & 35.5 weeks \\
\hline Take home baby rate & $35.4 \%$ & & $48.5 \%$ & $63.6 \%$ & $32.1 \%$ \\
\hline IUGR & $86.1 \%$ & $73.1 \%$ & $90 \%$ & & $79.1 \%$ \\
\hline Discordance & $9.5 \%$ & & & & 0 \\
\hline
\end{tabular}

We studied the various outcomes of fetal reduction by transvaginal route by using intracardiac puncture with OPU needle followed by aspiration of embryonic parts till asystole. Injection of $\mathrm{KCl}$ was avoided. 28 patients with higher order multiple pregnancies underwent fetal reduction and 29 non-reduced recruited as control group. We compared the various outcomes between reduced and non-reduced twins. It is a prospective comparative study

Transvaginal route was chosen because it was easy, can be done in earlier gestational ages. Most of the reductions were done between 8-12 weeks. Only one patient required early reduction at $7+6$ weeks which was a quadruplet pregnancy with bicornuate uterus, with 2 sacs in non-favourable horn. The average time required in all reductions varied between 20-30 minutes. There was no procedural difficulty, no one required second reduction

In the reduction group, 26 patients were triplets, 1 was quadruplet, 1 quintuplet. $42.9 \%$ higher order pregnancies were due to IVF and $25 \%$ were due to IUI who underwent reduction which clearly indicate that multiple pregnancy is an uncontrolled and an inevitable complication of ovulation induction. Infact quadruplet and quintuplet pregnancies were IUI pregnancies.

28 patients were reduced to twins, whereas one patient who had monochorionic diamniotic pregnancy with 2 sacs in one amniotic cavity was reduced to singleton so she was excluded from the study as it could have created a bias in the comparison

In a patient with quadruplet pregnancy in bicornuate uterus, 2 sacs in left horn were selectively reduced as left horn was small compared to right horn and was not suitable for pregnancy on previous interval hysteroscopy.

Another patient with quintuplets, 3 easily accessible embryos was reduced. In our study maximum 3 embryos have been reduced at a time. All were Dichorionic and Diamniotic in both reduced and non-reduced groups

Another patient with quintuplets, 3 easily accessible embryos was reduced. In our study maximum 3 embryos have been reduced at a time. All were Dichorionic and Diamniotic in both reduced and non-reduced groups

The mean age and parity of the patients were comparable in both groups. The mean age in reduced is 29.57 years Vs 28.8 years in control group.

The total abortion rate is $17.9 \%(n=5)$ in reduced group which is statistically significant. Among 5 patients, 3 aborted within a week of the procedure. All 3 patients had post procedure spotting. One patient aborted spontaneously after missed abortion at 12 weeks and another one at 17 weeks, a week after shirodkars cervical encirclage. Hence these two cannot be considered as immediate post procedure related losses. Procedure 
related loss rate is $10.7 \%$. No abortions in control group. No other significant immediate post procedure complications. The abortion rate in our study is comparable with other studies like $12.5 \%$ abortion rate in non KCL group (Lee et al), 7.3\% (Iberico et al), $8.8 \%$ (Mansour et al), $6.7 \%$ (Coffler et al), 8.8\% (Itskovitz et al), $13.1 \%$ (Evans et al). 4 patients were lost to follow up in the reduction group and none in control group. ${ }^{4,9,12-15}$

Lipitz et al, included 140 triplets, out of which 106 didn't undergo reduction and 34 patients underwent reduction to twins. Miscarriage rate was high $(25.4 \%)$ for expectantly managed triplets. ${ }^{16}$

Sebire and Nicolaides et al compared the outcomes of 127 multifetal pregnancies who underwent reduction with 354 nonreduced twin pregnancies by transabdominal intracardiac KCL. In the reduced twins, the miscarriage rate was higher $(12.6 \%$ vs $2.5 \%)$, the median gestation at delivery was lower (36 vs 37 weeks), median birth weight deficit was greater. The proportion of deliveries before 33 weeks was significantly greater in the reduced group compared to controls. ${ }^{17}$

In our study the rate of caesarean sections both elective $(58.6 \%$ vs $46.4 \%)$ as well as emergency (37.9 \% vs $14.3 \%$ ) increased in non-reduced twins probably because of associated medical and obstetric complications. However the value is not statistically significant. Reduced group had 2 normal deliveries.

Early preterm delivery is defined as deliveries between 28 weeks and 32 weeks. 3 patients $(10.7 \%)$ delivered in this period in reduced vs $2(6.9 \%)$ in control group. However 9 people $(32.1 \%)$ delivered between $32-36$ weeks in reduced group Vs $16(55.2 \%)$ people. But the difference in both the groups is not statistically significant.

The mean gestational age at delivery was 35 weeks (Iberico et al), 36.9 weeks (Mansour et al), 36 weeks (Lee et al) which is comparable with our study. 35.5 weeks in reduced group Vs 35.3 weeks.

The comparative study of the outcomes of triplet pregnancies reduced to twins versus the outcomes of expectantly managed triplet gestation by Yaron et al showed that the mean gestational age at delivery in nonreduced triplets was lower than non-reduced twins (32 weeks versus 35 weeks). The mean gestational age at delivery and birth weights were similar in reduced twins and non-reduced twins. ${ }^{18}$

The prospective, comparative and monocentric study by Boulot et al included 83 triplets managed expectantly and 65 underwent reduction to twins. Initial 16 cases underwent transcervical reduction with karmans cannula, remaining 49 cases with transabdominal intracardiac KCL. Reduction group had lower incidence of prematurity before 28 weeks, 32 and 34 weeks. The incidence of low birth weights was less. Neonatal and perinatal mortality didn't differ significantly. ${ }^{19}$

It is stated that increased early preterm delivery is probably related to embryonic remnant left behind after reduction which could have released thromboplastin from trophoblastic tissues or because of the widespread use o The hypothesis stated for early preterm delivery is the release of inflammatory cytokines in response to resorbing dead fetoplacental tissue. ${ }^{12}$

Alternative mechanism for preterm delivery is the decline in the hormonal support to the pregnancy such as human chorionic gonadotropin, estriol, within 2 weeks following fetal reduction. ${ }^{12}$

2 patients in reduced group (11.8\%) had PPROM compared to 4 patients in control group (14.3\%); the values are not statistically significant. One patient had chorioamnionitis in control group, no one in reduced group.

One patient in reduced group had discordant growth, none in control group. Birth weight discordance between surviving twins is increased with greater starting number like $>5(23.4 \%), 4(15.9 \%), 3(12.2 \%)$. The incidence of IUGR is also dependent on starting fetal number, increased circulating demands in the latter half of the pregnancy or due to uteroplacental insufficiency. ${ }^{9}$

The incidence of oligohydramnios is not statistically significant $(\mathrm{n}=1$ in reduced $\mathrm{Vs} \mathrm{N}=2$ control). Overall other obstetric complications are less in reduced group than in control group.

Totally 15 babies' required NICU admission, out of which 5 babies required oxygen after delivery (2 in reduced Vs 3 in control).

10 babies required ventilator support (4 in reduced Vs 6 in control ), 1 baby in control group died on post natal day 7 because of severe prematurity. The mother had chorioamnionitis and underwent emergency LSCS at $27+3$ weeks in view of advanced preterm labour. None of the babies required phototherapy for neonatal jaundice. No neonatal mortality in reduced group. The mean birth weight in reduced group was $2.2 \mathrm{~kg}$ and non-reduced group was $2.17 \mathrm{~kg}$. No incidence of IUGR in our series. Take home baby rate in reduced group is $79.1 \%, 98.2 \%$ in control group.

Overall perinatal and neonatal outcomes are comparable in both the groups. The mean birth weight was $3291 \mathrm{~g}$ (Iberico et al), $2450 \mathrm{~g}$ (Mansour et al), 2323g (Lee et al). ${ }^{4,12,13}$

3 patients had atonic $\mathrm{PPH}$ and required blood transfusion in control group, out of which one required global circlage. Only one patient had atonic PPH in reduced group. One patient in control group had laparotomy 
secondary to intestinal perforation. The post-operative complications were less in reduced group which was comparable with other studies.

Although most of the studies have reported improved outcomes with fetal reduction, 2 studies have contradictory results.

Melgar et al reported that the mean gestational age and birth weight were significantly lower in twins from reduced group than in nonreduced group, suggesting that reduction to twins may increase the risk of premature labour and birth. ${ }^{19}$

Similarly Porecco et al studied 11 sets of triplets and 13 sets of triplets reduced to twins, reported no statistically significant difference between both the groups with regard to birth weight, newborn complications, or number of days of hospital stay. ${ }^{20}$

Funding: No funding sources

Conflict of interest: None declared

Ethical approval: The study was approved by the Institutional Ethics Committee

\section{REFERENCES}

1. Berkowitz RL, Lynch L. The current status of multifetal pregnancy reduction. Am J Obstet Gynecol. 1996;174:1265-72.

2. Berkowitz RL, Lynch L, Lapinski R. First trimester transabdominal multifetal pregnancy reduction: A report of two hundred completed cases. Am J Obstet Gynecol. 1993;169:17-21.

3. Committee on Ethics, multifetal pregnancy reduction and selective fetal termination. Am coll of Obstetricians and Gynecologists, Washington. 1-3 ACOGCommittee Opinion no 94. 1991.

4. Iberico G, Navarro J, Blasco L, Simon C, Pellicer A, Remohi J. Embryo reduction of multifetal pregnancies following assisted reproduction treatment: A modification of the trans vaginal ultrasound - guided technique L, Simon C, Pellicer A, Remohi J. embryo reduction of multifetal pregnancies following assisted reproduction treatment: a modification of the trans vaginal ultrasound - guided technique. Hum reprod. 2000;15(10):2228-33.

5. Roze RJ, Tschupp MJ, Arvis PH. Interruption selective de grossesses et malformations embryonnaires des extremites. J.Gynecol Obstet Biol Reprod. 1989;18:673-7.

6. Tabsh KM. Transabdominal multifetal preganacy reduction: Report of 40 cases. Obstetric Gynecology. 1990;75:739-41.
7. Tabsh KM, Theroux NL. Genetic amniocentesis following multifetal pregnancy reduction to twins: assessing the risk. Prenat Diagn. 1995;15:221-3.

8. Lee JR, Ku SY, Jee BH, Suh CS, Kim KC. Pregnancy outcomes of different methods for multifetal pregnancy reduction: A comparative study. J Korean Med Sci. 2008;23(1):111-6.

9. Riffenburg RH. Statistics in Medicine, second edition, Academic press. 2005:85-125.

10. Suresh KP, Chandrasekhar S. Sample Size estimation and Power analysis for Clinical research studies. Journal Human Reproduction Science. 2012;5(1):7-13.

11. Evans MI, Richard L. Improvement in outcomes of multifetal pregnancy reduction with increased experience. Am J Obstet Gynecol. 2001;184: 97-103.

12. Mansour RT, Aboulghar MA, Serour GI. Multifetal pregnancy reduction: Modification of the technique and analysis of the outcome. Fertil Steril. 1999;71:380-4.

13. Lee JR, Ku SY, Jee BH, Suh CS, Kim KC. Pregnancy outcomes of different methods for multifetal pregnancy reduction: A comparative study. J Korean Med Sci. 2008;23(1):111-6.

14. Coffler MS, Kol S, Drugan A, Itskovitz-Eldor J. Early transvaginal embryo aspiration: a safer method for selective reduction in high order multiple gestations. Hum Reprod. 1999;14:1875-8.

15. Itskovitz-Eldor J, Drugan A, Levron J. Transvaginal embryo aspiration - a safe method for selective reduction in multiple pregnancies. Fertil. Steril. 1992;58:351-5.

16. Lipitz S, Frenkel Y, Watts C. Higher order multiple gestation: Management and outcome. Obstet and Gynecol. 1990;76:215-8.

17. Sebire NJ, Sherod C, Abbas A. Preterm delivery and growth restriction in multifetal pregnancies reduced to twins. Human Reprod. 1997;12:173-5.

18. Yaron Y, Bryant-Greenwood PK, Dave N, Molenhauer JS, Kramer RL. Multifetal pregnancy reductions of triplets to twins: comparison with nonreduced triplets and twins. Am J Obstet Gynecol. 1999;180:1268-71.

19. Boulot P, Hedon B, Pelliccia G. Effects of selective reduction in triplet gestation. Fertil Steril. 1993:497503.

20. Melgar CA, Rosenfeld DL, Rawlinson K, Greenberg M. Perinatal outcome after multifetal reduction of twins compared with multiple gestation. Obstet Gynecol. 1991;78:763-7.

21. RP Porreco. Multifetal reduction of triplets and pregnancy outcome. Obstet Gynecol. 1991;78:335-9.

22. Yousef H. Pregnancy outcome after multifetal reduction via early transvagianl embryo aspiration: Mansura fertility care unit experience. Middle East Fertility Society Journal. 2007;12(3):168-73.

Cite this article as: Gunasheela D, Rao S, Jain G, Anitha GS. Outcomes of transvaginal multifetal pregnancy reduction without injecting potassium chloride. Int J Reprod Contracept Obstet Gynecol 2017;6:182-9. 